\title{
SeaBASS: A Marine BioAcoustics Summer School 2014
}

\author{
Jennifer L. Miksis-Olds \\ Applied Research Laboratory \\ The Pennsylvania State University \\ PO Box 30 \\ State College, PA 16804 \\ phone: (814) 865-9318 fax: (814) 863-8783 email: j1m91@arl.psu.edu
}

Award Number: N000141410270

http://www.arl.psu.edu/education_seabass.php

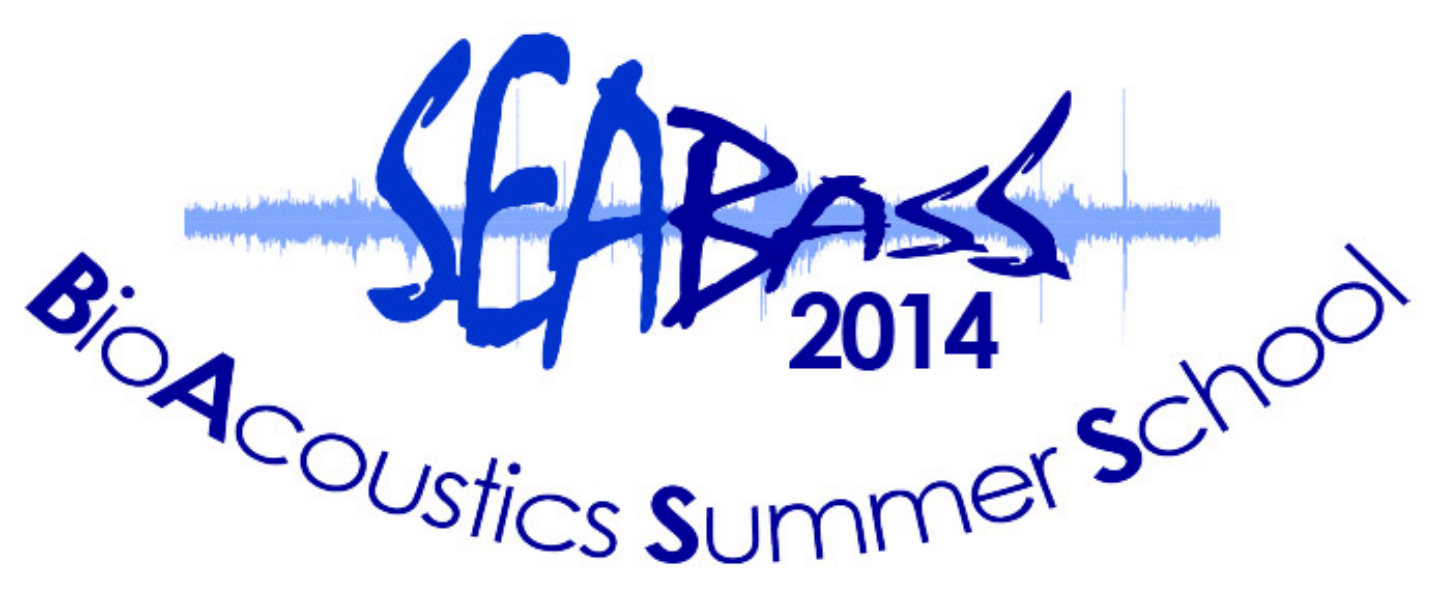

\section{LONG-TERM GOALS}

The goal of the SeaBASS (Marine BioAcoustics Summer School) was to provide the opportunity for graduate students interested in pursuing careers in marine bioacoustics to develop a strong foundation of both marine animal biology and acoustics, foster technical communication across disciplines, and develop professional relationships within the field. This course gave students an opportunity to learn from experts who discussed topics not often offered at universities due to the relatively small demand at any one institution.

\section{OBJECTIVES}

1. To provide fundamental concepts of underwater sound and marine animal biology and behavior to graduate students interested in pursuing careers in marine bioacoustics.

2. To create an environment for the open exchange of ideas related to careers, current hot topics, and challenges facing the field of marine bioacoustics. 


\section{Report Documentation Page}

Form Approved

OMB No. 0704-0188

Public reporting burden for the collection of information is estimated to average 1 hour per response, including the time for reviewing instructions, searching existing data sources, gathering and maintaining the data needed, and completing and reviewing the collection of information. Send comments regarding this burden estimate or any other aspect of this collection of information,

including suggestions for reducing this burden, to Washington Headquarters Services, Directorate for Information Operations and Reports, 1215 Jefferson Davis Highway, Suite 1204, Arlington

VA 22202-4302. Respondents should be aware that notwithstanding any other provision of law, no person shall be subject to a penalty for failing to comply with a collection of information if it

does not display a currently valid OMB control number.

\begin{tabular}{|c|c|c|}
\hline $\begin{array}{l}\text { 1. REPORT DATE } \\
\mathbf{3 0} \text { SEP } \mathbf{2 0 1 4}\end{array}$ & 2. REPORT TYPE & $\begin{array}{l}\text { 3. DATES COVERED } \\
\mathbf{0 0 - 0 0 - 2 0 1 4} \text { to 00-00-2014 }\end{array}$ \\
\hline \multirow{3}{*}{\multicolumn{2}{|c|}{ 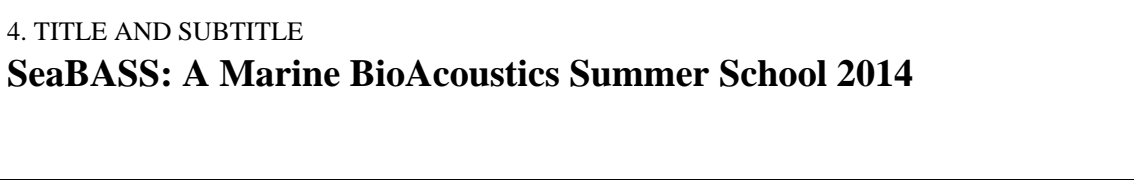 }} & 5a. CONTRACT NUMBER \\
\hline & & 5b. GRANT NUMBER \\
\hline & & 5c. PROGRAM ELEMENT NUMBER \\
\hline \multirow{3}{*}{\multicolumn{2}{|c|}{ 6. AUTHOR(S) }} & 5d. PROJECT NUMBER \\
\hline & & 5e. TASK NUMBER \\
\hline & & 5f. WORK UNIT NUMBER \\
\hline \multicolumn{2}{|c|}{$\begin{array}{l}\text { 7. PERFORMING ORGANIZATION NAME(S) AND ADDRESS(ES) } \\
\text { Pennsylvania State University,Applied Research Laboratory,PO Box } \\
\text { 30,State College,PA,16804 }\end{array}$} & $\begin{array}{l}\text { 8. PERFORMING ORGANIZATION } \\
\text { REPORT NUMBER }\end{array}$ \\
\hline \multirow{2}{*}{\multicolumn{2}{|c|}{ 9. SPONSORING/MONITORING AGENCY NAME(S) AND ADDRESS(ES) }} & 10. SPONSOR/MONITOR'S ACRONYM(S) \\
\hline & & $\begin{array}{l}\text { 11. SPONSOR/MONITOR'S REPORT } \\
\text { NUMBER(S) }\end{array}$ \\
\hline
\end{tabular}

12. DISTRIBUTION/AVAILABILITY STATEMENT

Approved for public release; distribution unlimited

13. SUPPLEMENTARY NOTES

14. ABSTRACT

15. SUBJECT TERMS

16. SECURITY CLASSIFICATION OF:

\begin{tabular}{c|c|c|c|}
$\begin{array}{c}\text { a. REPORT } \\
\text { unclassified }\end{array}$ & $\begin{array}{c}\text { b. ABSTRACT } \\
\text { unclassified }\end{array}$ & $\begin{array}{c}\text { c. THIS PAGE } \\
\text { unclassified }\end{array}$ & $\begin{array}{c}\text { Same as } \\
\text { Report (SAR) }\end{array}$
\end{tabular}

\begin{tabular}{c|l}
$\begin{array}{c}\text { 18. NUMBER } \\
\text { OF PAGES } \\
\mathbf{1 3}\end{array}$ & 19a. NAME OF \\
& \\
&
\end{tabular}


3. To foster professional relationships between graduate students and experts in the field.

\begin{abstract}
APPROACH
SeaBASS was structured after the successful PASS (Physical Acoustics Summer Session) program that has been offered in alternate years for over two decades. SeaBASS was designed to support 30 graduate students and 10 expert lecturers. A week long curriculm was created where invited lecturers within the field of marine animal bioacoustics (academic, private, and management) provided half day seminars that described fundamental aspects of underwater sound and marine animal behavior, summarized the present state of the field, identified current obstacles and challenges, and discussed important "hot topics" areas (Table 1). Each seminar included an introductory lecture followed by group discussions or group projects to gain a more in-depth understanding of the issues and technology. Structured social activities also allowed for students and presenters to interact informally to develop lasting professional mentorships for guiding the next generation of marine bioacoustics scientists.
\end{abstract}

SeaBASS 2014 was convened at The National Conference Center outside of Washington, DC. The week long summer session took place June 15-20, 2014. Selection of student participants was through an open application process. The application process was online (http://www.arl.psu.edu/education_seabass.php), and preference was given to US citizens.

ONR funds contributed support for Room and Board fees for all participants, conference facility fees, and travel grants to graduate student applicants based upon need and qualifications. Twenty one travel grants were awarded to defray costs of graduate student travel. Invited lecturers provided their time at no cost. Additional sponsors of the SeaBASS 2014 program included the Applied Research Laboratory at Penn State, the National Oceanic and Atmospheric Administration (NOAA), U.S. Marine Mammal Commission, LGL, Limited, StatOil, Shell Exploration \& Production Company, and the Acoustical Society of America (ASA). 
Table 1. SeaBASS 2014 schedule, topics, and presenters.

\begin{tabular}{|c|c|c|c|c|c|c|}
\hline & $\begin{array}{l}\text { Sunday } \\
\text { June } 15\end{array}$ & $\begin{array}{l}\text { Monday } \\
\text { June } 16\end{array}$ & $\begin{array}{l}\text { Tuesday } \\
\text { June } 17\end{array}$ & $\begin{array}{c}\text { Wednesday } \\
\text { June } 18\end{array}$ & $\begin{array}{l}\text { Thursday } \\
\text { June } 19\end{array}$ & $\begin{array}{l}\text { Friday } \\
\text { June } 20\end{array}$ \\
\hline 7:00-8:00 & & $\begin{array}{c}\text { Breakfast and } \\
\text { Welcome }\end{array}$ & Breakfast & Breakfast & Breakfast & Breakfast \\
\hline $8: 00-12: 00$ & & $\begin{array}{c}\text { A. Frankel } \\
\text { Introduction to } \\
\text { Acoustics \& } \\
\text { Propagation }\end{array}$ & $\begin{array}{l}\text { M. Halvorsen } \\
\text { Hearing and } \\
\text { Measurement }\end{array}$ & $\begin{array}{c}\text { A. Rice } \\
\text { Fish Acoustics and } \\
\text { Behavior }\end{array}$ & $\begin{array}{c}\text { H. Klinck } \\
\text { Passive Acoustic } \\
\text { Monitoring - } \\
\text { marine mammals }\end{array}$ & $\begin{array}{l}\text { S. Van Parijs } \\
\text { Communication } \\
\text { and Behavior }\end{array}$ \\
\hline $12: 00-13: 00$ & & Lunch & Lunch & Lunch & Lunch & $\begin{array}{c}\text { Lunch and } \\
\text { closing remarks }\end{array}$ \\
\hline $13: 00-17: 00$ & $\begin{array}{l}\text { Registration } \\
\text { opens 16:00, } \\
\text { Check-in } \\
\text { starts at 17:00 }\end{array}$ & $\begin{array}{c}\text { J. Warren } \\
\text { Active Acoustics }\end{array}$ & $\begin{array}{l}\text { L. Kloepper } \\
\text { Echolocation }\end{array}$ & $\begin{array}{c}\text { J. Miksis-Olds } \\
\text { Hot Topics in } \\
\text { Bioacoustics }\end{array}$ & $\begin{array}{c}\text { T. Marques } \\
\text { Density } \\
\text { Estimation from } \\
\text { PAM }\end{array}$ & $\begin{array}{c}\text { S. Parks } \\
\text { Effects of noise } \\
\text { on marine } \\
\text { mammals }\end{array}$ \\
\hline $18: 00-19: 30$ & Dinner & Dinner & Dinner & Dinner & Dinner & Adjournment \\
\hline $19: 30-22: 00$ & $\begin{array}{c}\text { Software } \\
\text { Installation, } \\
\text { Participant } \\
\text { Introductions }\end{array}$ & $\begin{array}{c}\text { Poster Session } \\
\text { and Social }\end{array}$ & Software demos & $\begin{array}{l}\text { Informal Career } \\
\text { Discussions with } \\
\text { presenters and } \\
\text { sponsors }\end{array}$ & $\begin{array}{c}\text { Evening bowling } \\
\text { event }\end{array}$ & \\
\hline
\end{tabular}




\section{WORK COMPLETED}

SeaBASS 2014 took place at the National Conference Center in Leesburg, VA from 15-20 June, 2014. Thirty graduate student applicants were admitted to the program from 70 eligible applications. A total of 4 applications and 21 informal inquiries were declined because they did not meet the course application and eligibility requirements:

- GPA 3.0 or higher during previous 2 years of study

- Currently enrolled in a Graduate program

- Personal Statement

Applications were received from graduate students in 19 countries (USA \& Puerto Rico, Italy, United Kingdom, Denmark, Canada, New Zealand, Portugal, Nigeria, Brazil, Uruguay, Poland, Turkey, Mexico, Ecuador, Slovenia, Peru, Malaysia, China, and Australia), and course attendees were accepted from 7 different countries (USA \& Puerto Rico, Italy, United Kingdom, Canada, Poland, Peru, and Australia). Advertising for SeaBASS was distributed on the MARMAM and ASA Bioacoustics listservs. Informational flyers were distributed at Acoustical Society of America meetings and the 20th Biennial Society of Marine Mammalogy Conference (New Zealand, 2013).

The SeaBASS curriculum included a general introduction to underwater sound, 8 specialized marine bioacoustics topics, and a "Hot Topics" session on the effects of sound on marine animals (Table 1). Invited speakers presented material in half-day sessions that included a traditional lecture covering fundamental topic concepts and an interactive activity consisting of analysis software demonstration and problem solving, experimental design exercises, group discussion, and a human echolocation exercise. Monday evening each student was given the opportunity to present a poster on their graduate research topic, methods, progress, or challenges. This gave students an opportunity to receive project feedback from peers and presenters. An informal career discussion took place mid-week where each invited presenter summarized their education and career path. Presenters openly shared personal experiences on issues not publically discussed in the field including family/career sacrifices, teaching vs research vs management pros/cons, value of post-doctoral experience, etc. Following the career synopses, students selected topics for additional round table discussions that consisted of family/career balance, challenges in a teaching career, pursuing post-doctoral positions, and obtaining research funding. Social activities provided the opportunity for informal interactions in the evening.

Abstract books were presented to each participant at registration and included course schedule, participant directory, lecture slides for select topics, group activity information, and suggested readings. Prior to the official opening of the SeaBASS program on Monday morning, students were able to download and become acquainted with software to be used in lectures and activities throughout the week.

\section{RESULTS}

A summary of the SeaBASS 2014 program is available to the public at http://www.arl.psu.edu/education_seabass.php. The site has a summary document for download that contains topic outlines, particiapnt and presenter list, and suggested readings for background information. SeaBASS participants were given the opportunity to formally evaluate the course through anonymous, online evaluation forms. Twenty-one evaluation forms were returned. Figure 1 summarizes the overwhelming positive response. 
Please rate the following aspects of the program on a scale of 1-5, where 1 is extremely poor and 5 is excellent.

Answered: 21 Skipped: 0

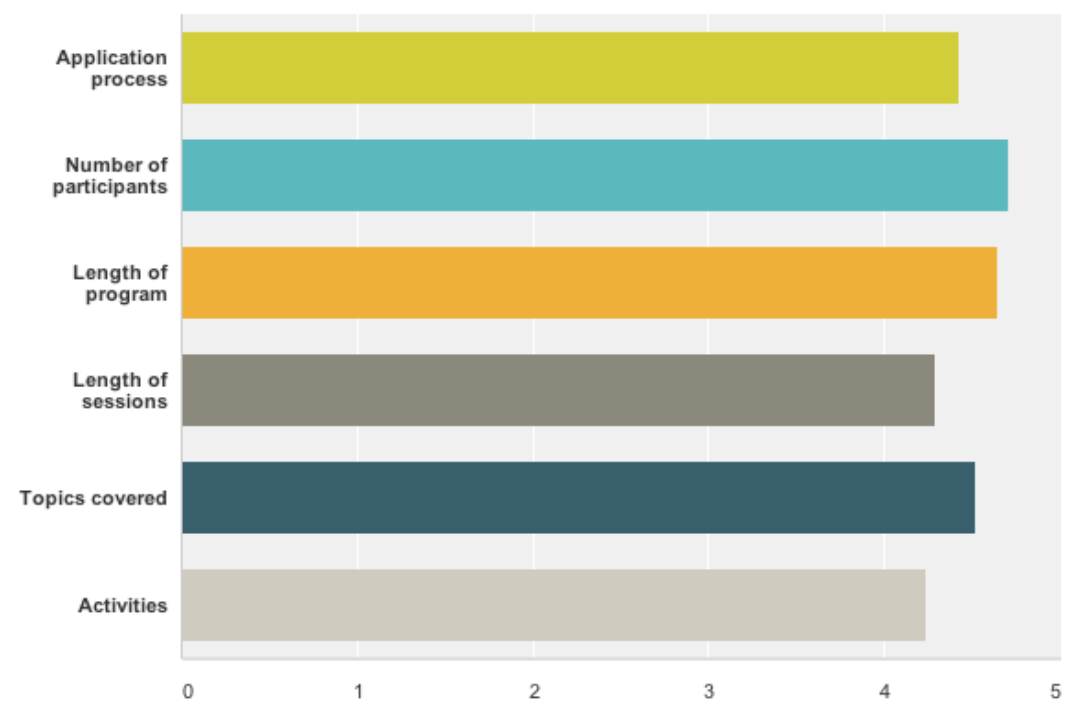

Program facilities: Please rate the following aspects of the conference center on a scale of 1 to 5 , where 1 is extremely poor and 5 is excellent.

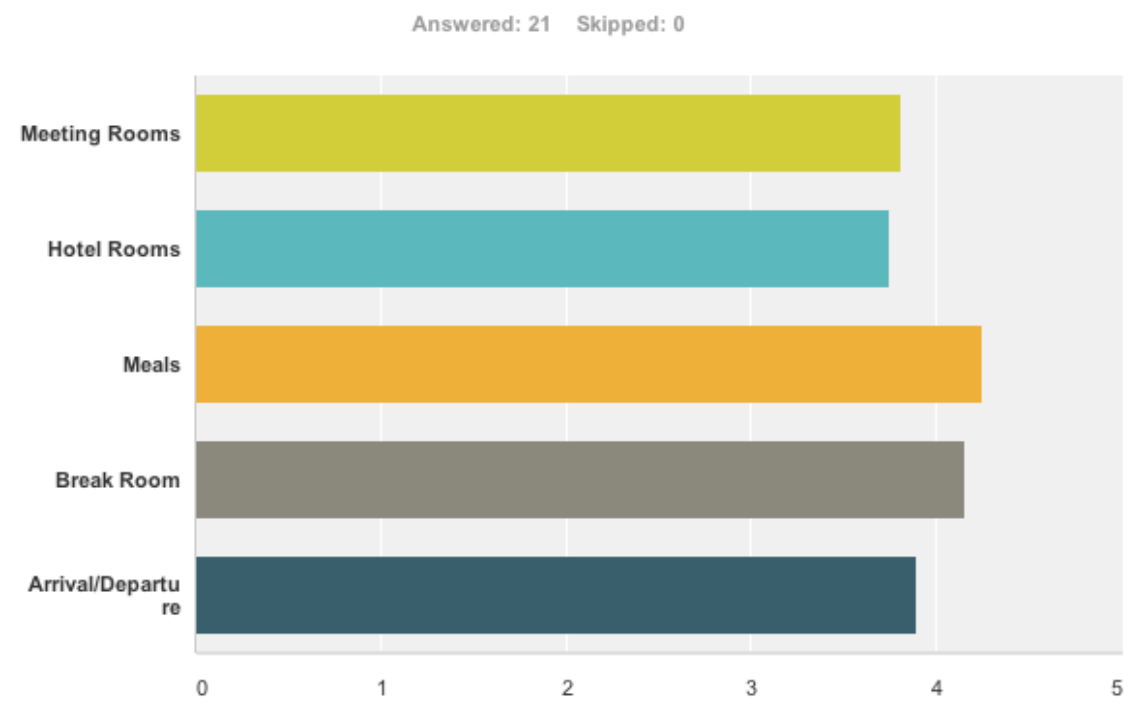

Figure 1. Summary of online evaluation questions and responses 


\section{What was your favorite topic lecture and why?}

- All the lectures were great, however if I should choose just one I would select Passive Acoustic Monitoring - just because it was the closest one to my personal interests and investigations.

- Passive Acoustic Monitoring - marine mammals and also Effects of noise on marine mammals, because they are strongly related to my $\mathrm{PhD}$ project.

- My favorite lectures were: Echolocation by L.Kloepper; Fish Acoustics and Behavior by A. Rice, Density Estimation using PAM by Marques, Communication and Behavior by Sofie and Effects of Noise on communication by Susan. The themes of the lectures were very exciting. I could see application of the topics on my and my collegues projects. the presenters were very carismatic and their knowledge about the topics brought the audicance curiosity and admiration to life.

- My favorite topic was the Fish and Marine Mammal hearing because I now have a better understanding of how fish and marine mammals hear and sense sound in the ocean.

Passive acoustic monitoring. I'd say probably because I'm a geek that loves to see how researchers are using technology to monitor these animals.

- Somewhat surprisingly, I enjoyed the Dr. Marques lecture on statistical concepts. I find that this is an area which often scares people away, and like me they end up with little background when reaching the post-graduate level when this knolwedge/skills are very important. I would love for Tiago to write a book or start a tutorial/webinar session on statistical concepts I think he has a gift for stats and a gift for teaching at a level that can be grasped by anyone. I also took away a tremendous amount of important back ground material from Dr. Frankel's lecture. Not the most exciting material to lecture about, but lots of great information was shared.

- Echolocation lecture-- I am interested in echolocation, and although I have seen many lecturers present on whistles or calls, I have never before seen a presentation solely on this vocalization type. Since I am interested in studying this topic in the future, I found this ridiculously helpful, and I found myself being very thankful to have been present for that lecture.

- It's hard to choose, because they were all great, but I really liked Adam's Lecture because it gave a fantastic intro to sound and sound analysis. I finally understand Fourier transforms! I also really liked Laura's lecture. She gave a fantastic presentation that was really interesting and really hands on, which was fun.

- My favorite was passive acoustic monitoring because it was the lecture that was both highly relevant to me and which I didn't already know a lot about. I think the introduction to acoustics and propagation and the hearing and measurement lectures are really important (though less fun).

- The vocalization detection and classification lecture because it is related to my research but not something taught in my home department. Very useful and valuable.

- PAM systems, Underwater sound propagations and density estimation. They were of my interest and close to my background. 
- Density estimation. has applications to my work, is a direction I see the field moving so good to learn about, speaker was engaging, activity was fun and directly applied

- I really enjoyed the lecture on density estimation. It was particularly helpful to learn some of the assumptions and limitations of a technique that is often oversimplified when cited as an application of passive acoustic monitoring.

- Session 1. Introduction to Acoustics \& Propagation This was my favorite because it answered many questions I had coming into the course about the technical lingo and settings of the various devices I use. It also helps to know what other acousticans look for in a published article or report.

- Echolocation. I didn't know much about it and Laura made it really interesting and interactive. Also, I really liked the career session. It was refreshing to hear different perspectives instead of the same perspectives that I get at my school.

- My favorite lecture was Laura's lecture on echolocation, not only because it's of special interest to me, but because her talk was extremely engaging and interesting.

- It is a tie between Joe Warren and Susan Parks. I liked Joe's because it showed how useful active acoustics can be and how accessible it is to people that have never used it. Usually you hear a lot about passive acoustics, but he showed that active acoustics is equally important. I liked Susan's because she shared a lot of her own research as case studies, and they were really interesting. Her work is also more applied than some of the other presenters and I think this is an important component of marine mammal research.

- It's a three way tie between [1] Fish Communication (Aaron), [2] Density Estimation (Tiago), and [3] Noise (Susan). Arron is a dynamic speaker who taught me something I didn't know, without talking down to us. I learned new things, both technically and topicwise. Tiago worked us through real world projects on a good topic. Susan integrated all of the topics and presented real world problems and solutions. It's very hard to pick though, the lectures were excellent. Joe and Laura both had really interesting dynamic talks. They were all really good. I feel like I have a TON of resources that I didn't have before I came. It was also a good refresher (and confidence boost) on the thing that I already knew.

- Adam's lecture on fish hearing, Joe's lecture on Active acoustics and tiago's lecture on distance sampling were all excellent. Not only were those three engaging lecturers and dynamic personalities, they provided both a baseline for students who had never seen the material before as well as some more in depth material.

- Density estimation - it was the field furthest from my own area of knowledge.

- Either the density estimation or the PAM for marine mammals. Mostly it was because these are the topics in my research. Though the presenters were also very engaging and had great activities.

- Density estimation. Excellent use of humor and incredibly applicable to my research

\section{What was your favorite hands on or group activity (or activities)? Why?}

- Analysis of acoustic data during Active Acoustic lecture and Tiago's statistical exercises they gave me quite a good picture of how does it all works in the real life 
- Passive Acoustic Monitoring - Density Estimation. It was very interactive and funny, and being outside was a nice change.

- The masking activity on Susan's lecture; the densisty estimation of haggis, the PAM planning on Sofie's lecture, the activities on Warren's lecture.

- I enjoyed the density estimation activity (LuuuuuuuuvHaggis). It was fun, but also provided a gentle introduction to get across the principles and possible hangups of conducting a real study.

- The echolocation activity-- Hands-on learning is not only a fabulous icebreaker to meet and become comfortable with others, but it also encouraged us to put our heads together to formulate an experiment and collaborate with new people, simulating an experience similar to one we'd encounter in the field.

- Sofie's activity where we planned out data collection plans for certain marine mammal species was not only a helpful exercise, but I also really enjoyed it.

- I liked the activities for determining if humans echolocate and estimation of the density of 'wild haggis'. I think these were a good balance fun activity, learning of the subject matter, and a chance to think about the experimentation process. I felt that for ever hands on activity which involved using a particular software that the activities were WAY too rushed for anyone who hadn't used the software before.

- Honestly, the more hands on activities, the better. Each hands on activity really helped ground a lot of the abstract topics being discussed. It's one thing to learn about how to estimate population density, but it's another to go through the calculations (active acoustics activity) and the estimation process 'in the wild' (the Haggis activity). I also really liked the activity built around observing the effects of anthropogenic noise by recording humans while they listened to noise that masked certain frequencies because it really made it hit home by having you physically experience it. Also, I really like the activity that focused around developing a plan for how to conduct a research study designed to impact governmental policy because it is something that we might all get involved in, and we need the fake experience to help us out when it's actually something we will be doing. I'm a huge fan of hands on activities, as it puts realizable experience into students. The first lectures on sound and sound propagation were great, but I was disappointed when time kept going over and we didn't have time for 'the hands on stuff' - but that's the best part! I was happy that we were later able to load up the software and use it. We could have had more of it, though.

- Raven software because it s a very good tool in my research.

- masking exercise (S. Parks). Great way to demonstrate the masking response, instructions were super clear so trying to figure out what to do did not distract from the point of the activity, allowed us to use what we learned about Raven early in the week in a directed way.

- I liked the management activity where groups had to collaboratively design a monitoring plan for a particular scenario. I am interested in conservation and management, so this type of real-world exercise was useful and engaging.

- Learning to use osprey and Ishmael. I had no idea these programs existed and yet they are very useful. 
- The echolocation activity and the activity for Sofie's activity about designing a monitoring scheme for a specific region. I thought the echolocation activity was good in that it taught us how to design experiments (which are often lacking in behavioral studies, since people often just observe animals in the wild) and I liked the monitoring activity because it helped us to think of management and how we can apply our knowledge about acoustics.

- I really enjoyed the density estimation activity and the masking activity.

- I liked working through Raven and estimating the density of Haggis. They were hands on, and applicable, and fun (and we got to go outside). The active acoustics activity was really really good (I've never done active acoustics before). I think Joe nailed the appropriate topic level for this audience, he was appropriately hard (we're graduate students it should be hard!).

- Estimating the haggis density

- The Haggis density estimation. It was fun to get outside after sitting inside all week. It would of been nice to have been able to help process the results as well, but we did run out of time.

- The haggis! Just a great exercise in teamwork and field work.

\section{Are there additional topics that you think should be covered in future SeaBass courses?}

- Maybe a lecture dedicated strictly to sound production mechanisms in marine mammals?

- It would be interesting to have a lecture (or part of a lecture) about acoustics in marine invertebrates, and to talk about sound production and/or reception in other groups of marine animals like sirenians and turtles.

- I would have liked to see a little more about sound production in marine mammals and more examples of successful acoustic based conservation initiatives examples.

- Not a new topic, but I think there would be benefit to more time devoted to lecture about active acoustics. Dr. Warren gave a good quick and dirty overview but it seemed there was much more material, which could have been presented, that couldn't be covered in just the one session.

- I was incredibly happy with many of the SeaBass topics, and cannot think of too many to add. Since we had a lecture on echolocation, maybe a lecture on well studied communicative signals? How to make your own hydrophone workshop?

- I think the breadth of topics covered was great. It would be nice (though I know we were crunched for time) to have bigger time slots devoted to working with the software.

- I think there was a good spread of topics.

- Keeping up to date and addressing hot topics seems like you'll always be on the forefront. The week was awesome, so I'm not sure what else to suggest.

- No.

- No specific topics. Several speakers mentioned not wanting to get into the math on certain things, but I found myself wanting a bit more in that area. I think that based on the vast range of experience of students this made sense, but I was initially under the impression this course was for PhD students only, so I expected it to be a bit more advanced in the 
topics because students would have some experience in the field rather than just a surface introduction of them. But I am sure the theory/intro/math balance is a difficult line to navigate.

- In general, I think the range of topics was appropriate for the course. However, it would have been nice to hear a presentation (possibly from some of the sponsor representatives) about specific management, mitigation, or policy changes that have come about as a result of acoustic monitoring.

- Session 1. Introduction to Acoustics \& Propagation could be an entire day worth of lecturing

- More about management and applications and progressing positive change. We need to learn how to apply our knowledge and how to communicate with non-scientists about our work so that other people and the ecosystem can benefit

- I think the behavioral ecology talk should have been a little more in-depth, possibly focusing more on specific behaviors of marine mammals and fishes.

- I cannot think of any additional topics! I was very pleased with the topics chosen for this SeaBASS meeting. It was a perfect balance, especially with the tie in to ecology at the end.

- More physics, more technical foundation. Sidebands, formants, attentuation (which was talked around, but never talked about), harmonics. The technical details of masking. Matlab and matlab resources.

- I think the breadth was satisfactory.

- This will give away while I am, but but more invertebrate information would be nice. I know they lack the specialization of fishes and marine mammals, but they make up $97 \%$ of the biota, and most inverts can detect sound

\section{What is the most valuable thing that you will take from SeaBass?}

- Connections with great people

- Tips and ideas that I can possibly apply to my project, as well as meeting lots of interesting people working in the same field.

- I believe that the people I met were the most valuable thing will take from SeaBass. All the participants became friends, colleagues, examples, incentives, motivators.

- A foundation of concepts and broadened exposure to the field. Connections. New ideas.

- The information / relationships

- The networking I was able to do at SeaBASS will go a long way. Not only networking with the presenters, but also with the other students. I gained valuable collaborators and friends.

- Personal connections made with others in the group. Also the evening career path discussions were really useful. Particularly the soft funding v. hard funding one.

- Seeing what's hot in the field. Meeting future collaborators. Gaining experience in the tools, ideas, and practices of bioacoustics.

- Friendship with a lot of people in my field, a broad knowledge of bioacoustics 
- A better understanding of the vast areas of bioacoustics outside of the little bit I work in. I like seeing the variety of work people are doing all over the world, that all get lumped under bioacoustics...especially the fish stuff! I learned about some tools that are out there and although you could never cover everything in one week, I feel like I learned how to go find more info when I need, including using the connections I made as a resource.

- Connections with other bioacousticians, particularly fellow students as well as professionals in non-academic fields.

- The connections to colleagues and knowledge gained on basic acoustics

- Information about future careers. It was helpful to hear everyone's career paths and the round table discussions about academia especially were very helpful since I only ever hear the perspective of working in a R1 institution.

- The networking opportunities were priceless.

- New networks, professional connections, and the many ways to study acoustics!

- All of it. The ability to synthesize across a broad range of acoustics topics, the relationships I formed professionally and personally. The breadth of resources that we were given. A sense of community. The encouragement to learn programming, to get better at acoustic tools, and to answer a new set of questions (that have legitimate biological implications).

- Definitely the connections with others in the field. There were wonderful opportunities for forming meaningful connections with both professors and students. I really appreciated the chance to talk science with people from a broad spectrum of backgrounds. The opportunities to interact were plentiful, and all professors seemed to do a good job of interacting with students.

- Friends and connections

- If you want something, work hard to get it. It's totally possible.

- That I really enjoy the more technical, mathematical side of underwater sound.

\section{Any additional comments?}

- Many thanks for inviting me! :)

- I loved the workshop. Thanks for organising it.

- This was a great program all around! Happy to have had opportunity to attend.

- I thought everything was really well done, and I personally got a ton of knowledge from this experience! The only real critique I have may be about the location/ conference center. The lack of reasonable internet was a bit troublesome during lectures for downloading material. However, on the bright side, it did bring a lot of corporation and teamwork to the table when passing about flash drives!! The abandoned facilities (overgrown pool, everlasting hallways) were also a bit as seen in a zombie film, but it definitely added some color and bonding to the experience, so not really a complaint there :)

- Thanks to Susan and Jen for all of your hard work to bring this together. Thanks also to all the great presenters for giving their time and for being open and approachable. A really awesome and unique experience! I will recommend to others. 
- Fantastic job! Thank you for the experience!

- So much fun! Thanks Susan and Jen for putting it all together!

- Make it clear what is expected out of student posters. - Should people be making posters on proposed projects? - Should people bring posters for non-acoustics work if that is all they have done which they could talk about? \{personally I think the answers to these should be YES\} or Should people only bring a poster if they have acoustics based work which is completed or which a part of has been completed (which is more like a conference and which would allow more useful critique of the posters themselves - but would potentially exclude more of the students\}

- I think this will prove to be the most important opportunity in my career for a long time to come.

- Thank you for offering this. It is a valuable opportunity.

- This week was amazing and important and extremely valuable. The social dynamic between students was very comfortable- I feel like I could call any of the students that were here and have a welcome conversation about science. I feel this way about most of the presenters (I could call Holger and ask him about gliders, I could call Susan and ask about right whales!). I certainly wouldn't feel shy about emailing any of the presenters and saying "Hi, I was your student at SeaBASS 2014 and I have a question about..." I can't thank you enough for putting this together and giving us this resource.

- Thanks! What a wonderful opportunity! A funded workshop is pretty special, and the focus on acoustics was really great! For me, it came at a great time. Thanks for all the work you put in to it, I know it's hard to meet everyone's needs and to plan something that is engaging without being overwhelming. Overall, everything went smoothly and was very interesting! I hope to stay in touch with everyone. Please don't hesitate to contact me with questions about my comments. -dave

- Thanks for putting on this event. It was great to meet everyone and learn about bioacoustics.

- I would LOVE to help out with future workshops if you guys need it

\section{IMPACT/APPLICATIONS}

The SeaBASS 2014 program allowed for extended interaction and discussion by students with each other and with leaders in the field of marine bioacoustics to define current and future research priorities and directions in the field. Evidence of the connections and collaborations made during SeaBASS 2014 is demonstrated by a SeaBASS student initiated, social media presence. SeaBASS 2014 students created a blog and Twitter feed to post information real-time throughout the week: http://blogs.oregonstate.edu/bioacoustics/2014/06/28/seabass-insiders-perspective-bioacousticsummer-school/. This is in addition to the online networks on Facebook (30 members) (https://www.facebook.com/groups/192730237521891/). You can now follow SeaBASS on Twitter! Subscribers have been using the online resources to exchange research ideas, seek feedback, solicit Matlab help, exchange information on upcoming conferences, and explore research funding opportunities. 


\section{TRANSITIONS}

SeaBASS provided training for graduate students in the growing field of marine animal bioacoustics. Expertise in this area will contribute to the Navy's need to understand how sound may potentially impact marine animals, how marine animals use sound, and how to effectively monitor for presence of marine animals.

\section{RELATED PROJECTS}

Not applicable at this time. 